\title{
Accumulation of toxigenic species of micromycetes as a factor of high phytotoxicity of urban soils
} Nazarenko N.N. ${ }^{1}$, Koretskaya I.I. ${ }^{2}$, Svistova I.D. ${ }^{2}$

\author{
${ }^{1}$ Voronezh state agrarian University, Voronezh, Russia; ${ }^{2}$ Voronezh state pedagogical University, Voronezh, Russia \\ E-mail: i.svistova@mail.ru
}

Key message. Indicator for urban load species of soil micromycetes synthesize mycotoxins of a wide range of toxic effects and
cause a significant increase in phytotoxic activity of the soil in the transport zone of the city. Keywords: urban soils, phytotoxic activity, toxigenic micromycetes

Phytotoxic activity of the soil is used as a parameter of biomonitoring of anthropogenic impact, the main factor of its growth is considered to be the accumulation of pollutants. The aim of the work was to study the role of soil micromycetes in the formation of phytotoxic activity of the soil of urban areas of the city of Voronezh.

Soil samples were taken by category of urban land. The number, species composition, and structure of the soil micromycetes complex were determined by spatial and temporal occurrence indicators. The phytotoxic activity of the soil was evaluated by the method of biotests on soil plates (test - radish plant).

The number of micromycetes in transport zones of the city was reduced by 3-4 times compared to recreation, and the phytotoxic activity of the soil increased by 5-6 times.

The species structure of the micromycete complex in urbolandscape soils is disturbed. The proportion of typical species of fungi increased in transport zone by comparison the recreation zone, which indicates a "concentration of dominance" and a decrease in diversity. In transport zones, the coefficient of similarity with the control amount only 0.2. Stenotopic species disappear: epiphytes, phytopathogens and saprotrophs that decompose plant residues: Cepalosporium acremonium, Acremonium alternatum, Paecilomyces lilacinum, Botrytis cinerea, Fusarium solani, Trichoderma koningii, Aspergillus ustus, Penicillium daleae, Mucor stolonifer.

The second group of species, rare or random in control, sharply increased the rank of dominance in the soils of urban landscapes: Aspergillus clavatus, A. alliaceus, A. terreus, A. flavus, A. ochraceus, A. fumigatus, Penicillium funiculosum, P. notatum, $P$. rubrum, $P$. purpurogenum, $P$. velutinum, $P$. viridicatum, Stachybotrys chartarum, Alternaria alternata, botryotrichum pipuliferum, they are indicative of urban load.

Common properties of indicator species are their ability to synthesize mycotoxins. The part of toxigenic species of micromycetes amount (\%): in control 11-14, in recreation 15-18, in residential zones 49-62, in transport zones 98-100. Strains isolated from the soil of Voronezh synthesize mycotoxins with a wide range of biological effects: antibiotic, fungicidal and phytotoxic, which determines their gain in the intensifying competition or the introduction of species in the depleted complex of urban soils.

Thus, the high phytotoxic activity of urbolandschaft soils is determined not only by the accumulation of pollutants, but also by the biotic factor, namely, the accumulation of toxigenic species of micromycetes.

\section{Накопление токсигенных видов микромицетов как фактор высокой фитотоксичности городских почв} Назаренко Н.Н. ${ }^{1}$ Кореикая И.И. ${ }^{2}$, Свистова И.Д. ${ }^{2}$

${ }^{1}$ Воронежский государственный аграрный университет, Воронеж, Россия; ${ }^{2}$ Воронежский государственный педагогический университет, Воронеж, Россия

\begin{abstract}
Аннотация. Индикаторные на городскую нагрузку виды почвенных микромицетов синтезируют микотоксины иирокого спектра токсического действия и обуславливают значительный рост фитотоксической активности почвы в транспортной зоне города.

Ключевые слова: городские почвы, фитотоксическая активность, токсигенные микромицеты

Фитотоксическая активность почвы используется как параметр биомониторинга антропогенного воздействия, основным фактором ее роста считается накопление поллютантов. Целью работы было изучение роли почвенных микромицетов в формировании фитотоксической активности почвы городских зон города Воронежа.

Пробы почвы отбирали по категориям городских земель. Определяли численность, видовой состав и структуру комплекса почвенных микромицетов по показателям пространственной и временной встречаемости. Фитотоксическую активность почвы оценивали методом биотестов на почвенных пластинах (тест-растение редис).

Численность микромицетов в транспортных зонах города снижена в 3-4 раза по сравнению с рекреациями, а фитотоксическая активность почвы возрастала в 5-6 раз.

Видовая структура комплекса микромицетов в почвах урболандшафтов нарушена. Доля типичных видов грибов возрастала в ряду рекреации < селитебная зона < транспортная зона, что свидетельствует о «концентрации доминирования» и снижении разнообразия. В транспортных зонах К сходства с контролем составлял 0,2. Исчезают стенотопные виды: эпифиты, фитопатогены и сапротрофы, разлагающие растительные остатки: Cepalosporium acremonium, Acremonium alternatum, Paecilomyces lilacinum, Botrytis cinerea, Fusarium solani, Trichoderma koningii, Aspergillus ustus, Penicillium daleae, Mucor stolonifer.

Вторая группа видов, редкие или случайные в контроле, резко повышала ранг доминирования в почвах урболандшафтов: Aspergillus clavatus, A. alliaceus, A. terreus, A. flavus, A. ochraceus, A. fumigatus, Penicillium funiculosum, P.notatum, P.rubrum, P. purpurogenum, P. velutinum, P. viridicatum, Stachybotrys chartarum, Alternaria alternata, Botryotrichum pipuliferum, они являются индикаторными на городскую нагрузку.

Общими свойствами индикаторных видов является их способность к синтезу микотоксинов. Доля токсигенных видов микромицетов составляла (в \%): в контроле 11-14, в рекреациях 15-18, в селитебных зонах 49-62, в транспортных зонах 98-100. Изоляты, выделенные из почвы г. Воронежа, синтезируют микотоксины с широким спектром биологического действия: антибиотического, фунгицидного и фитотоксического, что определяет их выигрыш в обостряющейся конкурентной борьбе или внедрение заносных видов в обедненный комплекс городских почв.

Таким образом, высокая фитотоксическая активность почв урболандшафтов определяется не только накоплением поллютантов, важный вклад вносит биотический фактор, а именно накопление токсигенных видов микромицетов.
\end{abstract}

